Perspective

\title{
Seawater desalination for agriculture by integrated forward and reverse osmosis: Improved product water quality for potentially less energy
}

\author{
Devin L. Shaffer ${ }^{\mathrm{a}}$, Ngai Yin Yip ${ }^{\mathrm{a}}$, Jack Gilron ${ }^{\mathrm{b}, 1}$, Menachem Elimelech ${ }^{\mathrm{a}, *}$ \\ a Department of Chemical and Environmental Engineering, Yale University, P.O. Box 208286, New Haven, CT 06520-8286, USA \\ ${ }^{\mathrm{b}}$ Zuckerberg Institute for Water Research, Ben-Gurion University of the Negev, Sde Boker 84990, Israel
}

\section{A R T I C L E I N F O}

\section{Article history:}

Received 21 March 2012

Received in revised form

6 May 2012

Accepted 7 May 2012

Available online 15 May 2012

Keywords:

Seawater desalination

Forward osmosis

Integrated process

Boron

Agriculture

Energy

\begin{abstract}
A B S T R A C T
Seawater desalination for agricultural irrigation will be an important contributor to satisfying growing water demands in water scarce regions. Irrigated agriculture for food production drives global water demands, which are expected to increase while available supplies are further diminished. Implementation of reverse osmosis, the current leading technology for seawater desalination, has been limited in part because of high costs and energy consumption. Because of stringent boron and chloride standards for agricultural irrigation water, desalination for agriculture is more energy intensive than desalination for potable use, and additional post-treatment, such as a second pass reverse osmosis process, is required. In this perspective, we introduce the concept of an integrated forward osmosis and reverse osmosis process for seawater desalination. Process modeling results indicate that the integrated process can achieve boron and chloride water quality requirements for agricultural irrigation while consuming less energy than a conventional two-pass reverse osmosis process. The challenges to further development of an integrated forward and reverse osmosis desalination process and its potential benefits beyond energy savings are discussed.
\end{abstract}

(c) 2012 Elsevier B.V. All rights reserved.

\section{Introduction}

Seawater desalination will play an important role in addressing the challenge of global water scarcity. The most important drivers for water scarcity are growing water demands from population growth, economic development, and increased per capita consumption of goods and services [1,2]. Specifically, the development of irrigated agriculture in response to increasing food demands from a growing population is the main driver behind water use [1]. Water demand estimates reflect these trends, with total global water demand dominated by agriculture (70\% of all global water use), followed by industrial use (21\%) and domestic use (9\%) [3].

While there is substantial uncertainty about the scale of future water demands, the world population and associated demand for food from irrigated agriculture is expected to increase significantly by $2050[1,4]$. Global climate change will also exacerbate water scarcity problems in the future [2]. As the single largest user of water, irrigated agriculture will come under acute pressure as water scarcity intensifies. The importance of irrigated agriculture in increasing food productivity, feeding a growing population, and reducing poverty,

\footnotetext{
* Corresponding author. Tel.: +1 203432 2222; fax: +1 2034327232

E-mail address: menachem.elimelech@yale.edu (M. Elimelech).

${ }^{1}$ On sabbatical leave at Yale University.
}

adds to the significance of water scarcity as a major human development challenge [5]. Continued research and the development of new treatment technologies are needed to improve the availability and quality of water supplies for the benefits of improved public health, economic vitality, and environmental quality [6].

Seawater or brackish water desalination, and wastewater reclamation and reuse are the only methods to increase water supply beyond what is available from the hydrological cycle [6,7]. Consequently, desalination technologies will play an important role in solving global water scarcity problems. Seawater desalination offers the potential for an abundant and drought-proof source of fresh water that may be the only viable means for some water-scarce regions to meet demands [8].

The widespread implementation of seawater desalination technology is currently limited by complex economic, social, environmental, and political factors. Seawater reverse osmosis (SWRO) has emerged as the leading technology for future seawater desalination facilities because of its relatively low energy consumption and produced water cost compared to thermal desalination technologies [9]. However, the real and perceived costs and energy requirements of seawater desalination continue to be a barrier to its implementation [10,11], especially seawater desalination for agricultural use. Because of stringent boron and chloride standards for agricultural irrigation water, desalination for agriculture is more energy intensive than desalination for potable use. Innovations that 
reduce energy consumption will decrease costs and improve the sustainability of SWRO, thereby strengthening its suitability for addressing long-term water needs [12].

A combined seawater desalination process using emerging forward osmosis technology coupled with reverse osmosis could potentially reduce the energy consumption of the seawater desalination process, and thus, lower barriers to its implementation. In this perspective article, we discuss a combined forward and reverse osmosis desalination process that could lower the total energy of desalination through reductions in pretreatment and post-treatment requirements. The important example of SWRO to produce agricultural irrigation water is examined.

\section{Pretreatment and post-treatment technologies consume a significant fraction of the energy of SWRO desalination}

A typical SWRO process consists of a seawater intake, pretreatment system, high pressure pumping system, reverse osmosis desalination stages, permeate post-treatment, product water storage, and distribution [13]. The goal of the pretreatment process is to reduce fouling and scaling of the reverse osmosis membranes, and it is typically accomplished using chemical addition and either conventional granular media filtration or membrane micro- or ultrafiltration. The reverse osmosis desalination component uses applied hydraulic pressure to oppose, and exceed, the osmotic pressure of seawater. Seawater is purified by semipermeable RO membranes that allow water to pass but reject dissolved salts through a solution-diffusion mechanism [9].

Post-treatment is a finishing step to prepare the reverse osmosis permeate for distribution and use. Depending on the seawater characteristics and specified product water requirements, post-treatment may include additional reverse osmosis passes to achieve the desired product water quality. SWRO facilities that produce water for agricultural irrigation employ multiple reverse osmosis passes to reduce boron and chloride to low concentrations that cannot be achieved in a single pass, even with advanced, high-rejection membranes [14]. Post-treatment also includes chemical addition to remineralize and stabilize the permeate by increasing the hardness and alkalinity [9].

Each of the components in the SWRO process consumes energy and contributes to the total energy of desalination, which ranges from $3-7 \mathrm{kWh} / \mathrm{m}^{3}$ of produced water for existing SWRO plants $[10,15]$. The energy requirements for seawater desalination are related to the feed water salinity and the targeted product water quality [10]. The most stringent product water require- ments are often specified for water used for agricultural irrigation because of the sensitivity of some crops to relatively low boron and chloride concentrations. The more stringent product water requirements for agricultural irrigation water impose a greater energy cost for SWRO desalination.

Boron exists in seawater primarily as boric acid, and its concentration ranges from 4.5-6.0 mg/L [9]. World Health Organization drinking water guidelines recommend a maximum boron concentration of $2.4 \mathrm{mg} / \mathrm{L}$ for health protection and maximum total dissolved solids and chloride concentrations of $1000 \mathrm{mg} / \mathrm{L}$ and $250 \mathrm{mg} / \mathrm{L}$, respectively, for water palatability reasons [16]. Recommended concentrations for agricultural irrigation water are more restrictive. A boron concentration less than $0.50 \mathrm{mg} / \mathrm{L}$, total dissolved solids concentration less than $450 \mathrm{mg} / \mathrm{L}$, and chloride concentration less than $105 \mathrm{mg} / \mathrm{L}$ are recommended to prevent damage to sensitive crops [17]. A related measure of irrigation water quality is the sodium adsorption ratio (SAR), which is calculated from the concentrations of sodium, calcium, and magnesium ions. SAR affects soil infiltration rates, and a SAR less than 3 (i.e., relatively lower sodium ion concentration) is recommended for irrigation water with a low total dissolved solids concentration [17]. In practice, seawater desalination facilities that produce water for agricultural irrigation are designed to produce water with low boron concentrations between 0.3 and $1.0 \mathrm{mg} / \mathrm{L}$ [14] and total dissolved solids concentrations between 200 and $500 \mathrm{mg} / \mathrm{L}$ [10].

Because of the significant and increasing global water demands for irrigated agriculture, and the potential role of seawater desalination in meeting these demands in the context of growing water scarcity, it is instructive to examine the energy requirements for a SWRO facility that is specifically designed to treat water to the stringent boron and chloride concentration requirements for irrigated agriculture. Some arid regions of the world, including Israel [18] and Spain [19], have already implemented or are planning to implement seawater desalination facilities that produce water ultimately to be used for agricultural irrigation.

Fig. 1 illustrates a SWRO process that includes post-treatment reverse osmosis passes for boron and chloride removal and identifies the energy requirements of each component in the desalination process. The reverse osmosis desalination stage has the largest energy demand, consuming $2-5 \mathrm{kWh} / \mathrm{m}^{3}$ of produced water $[10,15]$. Seawater pretreatment can consume $0.2-0.4 \mathrm{kWh} / \mathrm{m}^{3}$ of produced water, while post-treatment for permeate stabilization and remineralization is typically less than $2 \%$ of the total energy required for desalination [15]. Post-treatment for boron and chloride removal by a second reverse osmosis pass is estimated to require $0.5 \mathrm{kWh} / \mathrm{m}^{3}$ of produced water [20]. In practice, some SWRO facilities, such

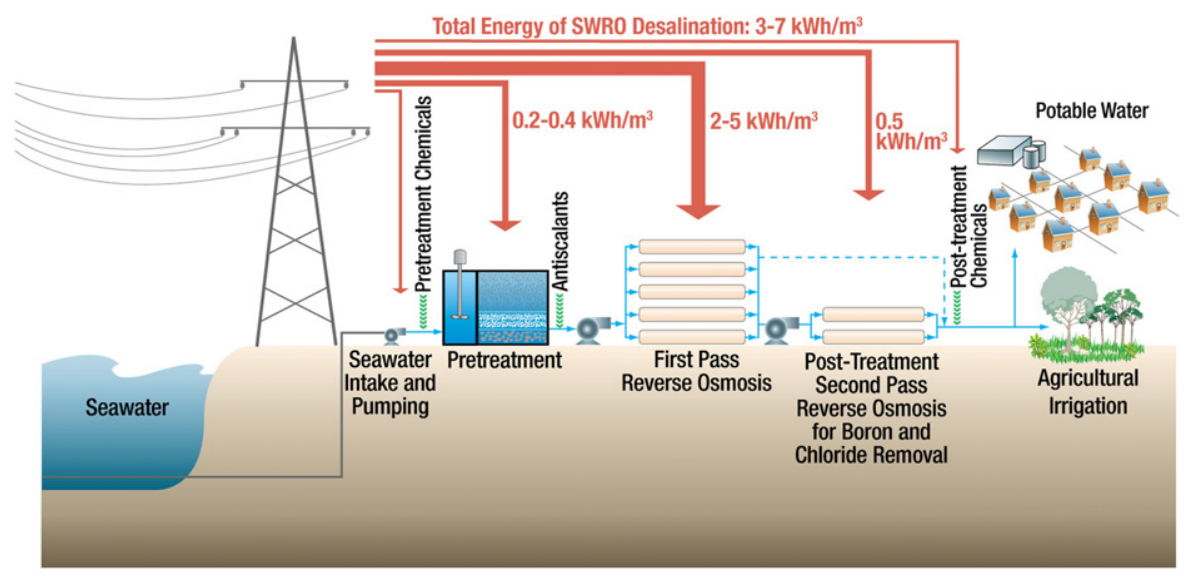

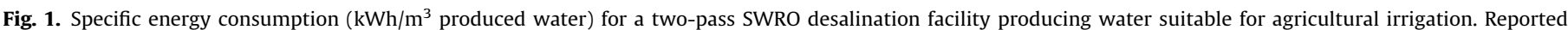
specific energy consumption values depend on the feed water quality, extent of the SWRO process included, use of energy recovery devices, and other factors. 
as the Ashkelon facility in Israel, use a combination of multiple reverse osmosis passes and stages for boron and chloride posttreatment [14]. The total energy consumption of a state-of-the art SWRO facility producing agricultural irrigation water is in the range of $3-7 \mathrm{kWh} / \mathrm{m}^{3}$ of produced water $[10,15]$. For this type of facility, Fig. 1 illustrates that pretreatment and post-treatment can consume a combined $0.7-0.9 \mathrm{kWh} / \mathrm{m}^{3}$ of produced water, which is a significant portion of the total energy of desalination.

\section{Reducing energy for pretreatment and post-treatment is key to further SWRO energy savings}

Improvements in membrane technology and the use of highefficiency energy recovery devices have dramatically reduced the energy consumption of the reverse osmosis stage in SWRO to nearly $2 \mathrm{kWh} / \mathrm{m}^{3}$ of produced water when operating at $50 \%$ recovery [8]. This value is within a factor of two of the theoretical minimum value for seawater desalination and is approaching the practical minimum energy of desalination, which is approximately $1.5 \mathrm{kWh} / \mathrm{m}^{3}$ of produced water [8]. The practical minimum energy is a limit set by thermodynamics, and thus, further energy reductions from the reverse osmosis process are expected to be only small incremental improvements resulting from more efficient equipment or system modifications [8]. Other aspects of the SWRO treatment process must be targeted to reduce the overall energy of desalination.

The pretreatment and post-treatment processes are two promising areas for additional, economically significant reductions in the energy of SWRO. Reductions in the extent of required pretreatment to prevent membrane fouling and scaling could reduce energy consumption [8]. Less frequent and intense membrane cleanings as a result of better pretreatment or the development of foulingresistant membranes could also result in energy savings [10]. Improved rejection of boron and chloride in the primary reverse osmosis process could eliminate the equipment and energy associated with additional reverse osmosis stages for boron and chloride post-treatment.

The pretreatment and post-treatment processes in SWRO have not been optimized to the same extent as the reverse osmosis process. Reducing the energy requirements of pretreatment for the typical SWRO process is difficult because progress in the development of a fouling-resistant reverse osmosis membrane has been slow. The surface properties of the thin-film composite polyamide membranes used in SWRO make them prone to fouling and pretreatment is necessary to maintain process performance [8]. Similarly, the development of reverse osmosis membranes with high boron and chloride rejection that could reduce the post-treatment requirements for SWRO has been impeded by the permeability-selectivity tradeoff of polymeric membranes $[21,22]$. Increasing the rejection of boron and chloride of reverse osmosis membranes will result in reduced water permeability, therefore requiring an overall increase in energy consumption to maintain the same water production.

Reducing pretreatment requirements through improved reverse osmosis membranes alone will require major improvements in membrane chemistry to resist fouling. Post-treatment energy savings from improved boron and chloride rejection in a single reverse osmosis pass will necessitate a shift to novel membranes that do not follow the solution-diffusion mechanism in order to avoid the permeability-selectivity tradeoff [8], or it will require the development of a new and better performing material for the membrane selective layer. However, a novel approach that employs a combined forward osmosis and reverse osmosis desalination process with existing membrane technology has the potential to achieve both pretreatment and post-treatment energy savings by combining seawater pretreatment and removal of boron and chloride into a single integrated process.

\section{Integrated forward osmosis and reverse osmosis is a practicable desalination process}

Forward osmosis employs the osmotic pressure difference between a feed solution, such as seawater, and a more concentrated draw solution to transport water from the feed through a saltrejecting membrane into the draw. In reverse osmosis, the applied pressure to the seawater feed solution is the driving force for mass transport through the membrane. However, in forward osmosis, the osmotic pressure difference between the feed solution and the more concentrated draw solution is the driving force for mass transport [23]. Draw solutions for forward osmosis are typically composed of pure water and a draw solute that is selected for its ability to produce high osmotic pressures, limited reverse solute flux through the membrane into the feed solution, and low propensity for membrane fouling and scaling [24]. In a continuous forward osmosis process, the draw solution, which is diluted by extracting water from the feed solution, is regenerated. Regeneration separates the dilute draw solution into the desired product water and a concentrated draw solution that is recycled to the forward osmosis unit.

An integrated forward osmosis and reverse osmosis process for seawater desalination is illustrated in Fig. 2. In this combined process, forward osmosis acts as a pretreatment stage for a reverse osmosis process that permeates product water and regenerates the draw solution, which is then recycled to the forward osmosis process. The propensity for irreversible fouling is much lower for the forward osmosis process than reverse osmosis [25]. Thus, the forward osmosis unit can function as a pretreatment step for the subsequent reverse osmosis unit while requiring only periodic physical scouring and/or osmotic backwashing to restore flux lost to fouling. An integrated forward and reverse osmosis process has the potential to achieve low boron and chloride concentrations without requiring additional post-treatment reverse osmosis passes because the treated seawater must pass through two selective membranes as part of the treatment scheme.

The feasibility of a combined forward osmosis and reverse osmosis process has been the subject of recent research. Modeling of an integrated forward osmosis and reverse osmosis seawater desalination system was conducted using bench-scale experimental data for a forward osmosis unit with seawater as the feed and concentrated $\mathrm{NaCl}$ solution as the draw solution [26,27]. In addition, bench-scale testing of an integrated system combining forward osmosis and nanofiltration membranes has been performed for brackish water desalination [28] and seawater desalination [29]. Integrated forward and reverse osmosis has also been investigated at a pilot scale for osmotic dilution and subsequent treatment of wastewater effluent [30].

These modeling exercises and bench- or pilot-scale experiments have indicated that integrated forward osmosis and reverse osmosis is a practicable desalination process with potential benefits of lower energy requirements for pretreatment, simplified pretreatment with reduced chemical usage, and reduced fouling and extended life of the subsequent reverse osmosis process $[27,28]$. Some challenges have also been identified for continuous operation of an integrated system with a draw solution closed loop. The most significant challenge is the reverse flux of the draw solute through the forward osmosis membrane from the concentrated draw solution into the more dilute feed solution $[27,30]$. The loss of draw solute reduces the concentration of the draw solution and the osmotic driving force for forward osmosis and would require continuous addition of draw solute to maintain the performance of the integrated forward osmosis and reverse osmosis system. Fig. 2 illustrates a flowstream for draw solution makeup to maintain the osmotic pressure of the draw solution.

The challenge of reverse draw solute flux can be addressed through improved forward osmosis membrane design and draw 


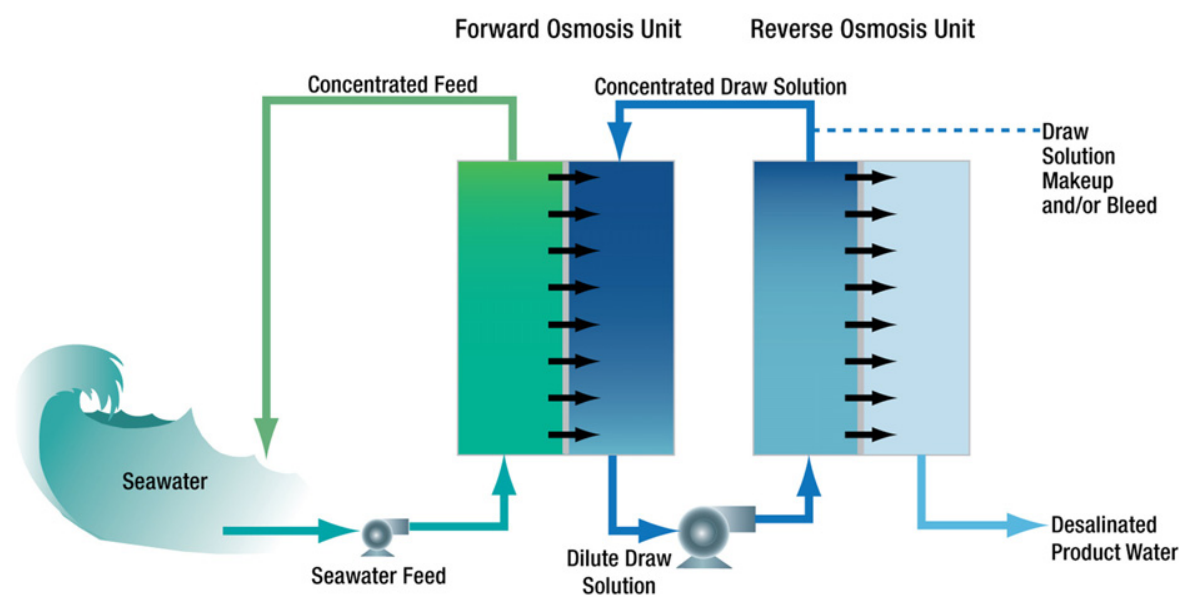

Fig. 2. An integrated forward osmosis and reverse osmosis desalination process.

Table 1

Integrated forward and reverse osmosis seawater desalination process modeling conditions.

\begin{tabular}{|c|c|c|c|}
\hline Modeling conditions & Value & Units & Reference/Remarks \\
\hline Seawater feed flow rate, $Q_{F}$ & 100,000 & $\mathrm{~m}^{3} /$ day & \\
\hline Forward osmosis process recovery, $Y_{\mathrm{FO}}$ & 25 & $\%$ & \\
\hline Draw solution flow rate as a ratio of feed solution flow rate, $Q_{D}$ & 1.0 & $\times Q_{\mathrm{F}}$ & \\
\hline Draw solution osmotic pressure, $\pi_{\mathrm{D}}$ & 1.5 & $\times \pi_{\mathrm{C}}$ & $\begin{array}{l}\text { One and a half times the osmotic pressure of the } \\
\text { forward osmosis process concentrated feed, } \pi_{\mathrm{C}} \text {. }\end{array}$ \\
\hline Reverse osmosis process operating pressure multiplier, $\Delta P_{\mathrm{RO}}$ & 1.0 & $\times \pi_{\mathrm{D}}$ & $\begin{array}{l}\text { Equals the osmotic pressure of the reverse osmosis } \\
\text { process retentate/forward osmosis process draw solution }\end{array}$ \\
\hline Seawater feed osmotic pressure, $\pi_{\mathrm{F}}$ & 29.7 & bar & \\
\hline Seawater feed boron concentration, $C_{\mathrm{F}(\mathrm{B})}$ & 4.5 & $\mathrm{mg} / \mathrm{L}$ & [9] \\
\hline Seawater feed TDS concentration, $C_{\mathrm{F}(\mathrm{TDS})}$ & 35,000 & $\mathrm{mg} / \mathrm{L}$ & [10] \\
\hline Seawater feed chloride concentration, $C_{\mathrm{F}(\mathrm{Cl})}$ & 19,000 & $\mathrm{mg} / \mathrm{L}$ & [10] \\
\hline Seawater feed concentration of $\mathrm{MgSO}_{4}$ draw solute, $C_{\mathrm{F}\left(\mathrm{MgSO}_{4}\right)}$ & 0 & $\mathrm{mg} / \mathrm{L}$ & \\
\hline Reverse osmosis process high pressure pump efficiency, $\eta_{\text {Pump }}$ & 100 & $\%$ & \\
\hline Pressure exchanger efficiency, $\eta_{\mathrm{PX}}$ & 100 & $\%$ & \\
\hline Membrane water permeability coefficient, $A$ & 2.1 & $\mathrm{Lm}^{-2} \mathrm{~h}^{-1} \mathrm{bar}^{-1}$ & [39] \\
\hline Membrane structural parameter, $S$ & 300 & $\mu \mathrm{m}$ & [34] \\
\hline Mass transfer coefficient of feed solutes, $k$ & 38.5 & $\mu \mathrm{m} / \mathrm{s}$ & {$[40]$} \\
\hline Bulk diffusion coefficient of draw solute in water, $D_{\left(\mathrm{MgSO}_{4}\right)}$ & 0.373 & $\times 10^{-9} \mathrm{~m}^{2} / \mathrm{s}$ & {$[41]$} \\
\hline Membrane permeability coefficient for chloride, $B_{\mathrm{Cl}}$ & 0.16 & $\mathrm{Lm}^{-2} \mathrm{~h}^{-1}$ & [39] \\
\hline Membrane permeability coefficient for boron, $B_{\mathrm{B}}$ & 1.53 & $\mathrm{Lm}^{-2} \mathrm{~h}^{-1}$ & {$[42]$} \\
\hline Membrane permeability coefficient for $\mathrm{MgSO}_{4}$ draw solute, $B_{\left(\mathrm{MgSO}_{4}\right)}$ & 0.0402 & $\mathrm{Lm}^{-2} \mathrm{~h}^{-1}$ & Estimated from $[41]^{\mathrm{a}}$ \\
\hline Absolute temperature, $T$ & 298 & $\mathrm{~K}$ & \\
\hline
\end{tabular}

${ }^{\text {a }} B_{\left(\mathrm{MgSO}_{4}\right)}$ was estimated by multiplying $B_{\mathrm{Cl}}$ by the ratio of diffusion coefficients for $\mathrm{MgSO}_{4}$ and chloride. $B_{\left(\mathrm{MgSO}_{4}\right)}=B_{\mathrm{Cl}}\left(D_{\left(\mathrm{MgSO}_{4}\right)} / D_{\mathrm{Cl}}\right)=0.251 B_{\mathrm{Cl}}$.

solute selection. The reverse flux selectivity of the forward osmosis membrane, which is defined as the volume of water produced per mass of draw solute lost by reverse flux, is determined solely by the selectivity and permeability of the membrane and the ability of the draw solute to generate an osmotic pressure [31]. Consequently, the development of a high-rejection forward osmosis membrane and the use of draw solutes that are more easily rejected by the membrane will dramatically reduce the reverse draw solute flux.

The boron and salt rejections of the commercial asymmetric forward osmosis membrane have also been the subjects of recent study. Boron rejection (as boric acid) was less than that of commercial thin-film composite SWRO membranes operating under similar conditions [32,33]. Salt $(\mathrm{NaCl})$ rejection of the forward osmosis membrane has also been observed to be less than SWRO membranes [31]. Thus, the development of a highrejection forward osmosis membrane can improve boron and salt removal, in addition to minimizing reverse draw solute flux.

Currently, modeling efforts and bench-scale experiments of combined forward and reverse osmosis processes have used the first generation, commercially available, cellulose acetate forward osmosis membrane. Prototype, second-generation, thin-film composite polyamide membranes for forward osmosis have been fabricated in a laboratory setting, and these membranes have been demonstrated to achieve a flux and selectivity that is superior to the commercially available cellulose-based membranes [34,35]. Draw solute selection can also improve the performance of the forward osmosis process. Research indicates that salt solutions with largersized hydrated anions, such as $\mathrm{MgSO}_{4}$ and $\mathrm{Na}_{2} \mathrm{SO}_{4}$, are better rejected by the forward osmosis membrane [24,29].

To demonstrate the practicability of integrated forward and reverse osmosis desalination, we modeled the process and estimated the product water quality at total integrated system recoveries of $10,25,50$, and $70 \%$. Seawater was the feed stream, and the model assumed second-generation thin-film composite forward osmosis membranes with total dissolved solids rejection and boron rejection equivalent to high-rejection SWRO membranes. Table 1 summarizes the process modeling conditions. Table 2 presents the key permeate water quality and system performance results of the modeling for an overall system recovery of $25 \%$. 
Table 2

Integrated forward and reverse osmosis seawater desalination process modeling results at $25 \%$ overall system recovery.

\begin{tabular}{|c|c|c|c|c|}
\hline Modeling results & Value & Units & Calculation & Reference \\
\hline Draw solution $\mathrm{MgSO}_{4}$ concentration, $C_{\mathrm{D}\left(\mathrm{MgSO}_{4}\right)}$ & 144,000 & $\mathrm{mg} / \mathrm{L}$ & $C_{\mathrm{D}\left(\mathrm{MgSO}_{4}\right)}=\pi_{\mathrm{D}} / n R_{\mathrm{g}} T$ & van't Hoff equation \\
\hline \multirow[t]{2}{*}{ Total integrated system boron rejection, $R_{\mathrm{T}(\mathrm{B})}$} & 95.0 & $\%$ & $R_{\mathrm{T}(\mathrm{B})}=R_{\mathrm{FO}(\mathrm{B})}+R_{\mathrm{RO}(\mathrm{B})}-R_{\mathrm{FO}(\mathrm{B})} R_{\mathrm{RO}(\mathrm{B})}$ & {$[36]$} \\
\hline & & & $R_{\mathrm{B}}=1-\frac{B_{\mathrm{B}}}{\left(B_{\mathrm{B}}+J_{\mathrm{w}}\right)}$ & {$[33]$} \\
\hline \multirow[t]{2}{*}{ Total integrated system chloride rejection, $R_{\mathrm{T}(\mathrm{Cl})}$} & 99.9 & $\%$ & $R_{\mathrm{T}(\mathrm{Cl})}=R_{\mathrm{FO}(\mathrm{Cl})}+R_{\mathrm{RO}(\mathrm{Cl})}-R_{\mathrm{FO}(\mathrm{Cl})} R_{\mathrm{RO}(\mathrm{Cl})}$ & {$[36]$} \\
\hline & & & $R_{\mathrm{Cl}}=1-\frac{B_{\mathrm{Cl}}}{\left(B_{\mathrm{Cl}}+J_{\mathrm{w}}\right)}$ & {$[33]$} \\
\hline \multirow[t]{2}{*}{ Boron concentration in reverse osmosis process permeate, $C_{\mathrm{P} 2(\mathrm{~B})}$} & 0.04 & $\mathrm{mg} / \mathrm{L}$ & $C_{\mathrm{P} 2(\mathrm{~B})}=\left(J_{\mathrm{B}} A_{\mathrm{ROmem}}\right) / Q_{\mathrm{P} 2}$ & \\
\hline & & & $J_{\mathrm{B}}=\frac{B_{\mathrm{B}}}{1+\left(B_{\mathrm{B}} / J_{\mathrm{w}}\right)} C_{\mathrm{P} 1(\mathrm{~B})}$ & {$[33]$} \\
\hline \multirow[t]{2}{*}{ Chloride concentration in reverse osmosis process permeate, $C_{\mathrm{P} 2(\mathrm{Cl})}$} & 3.9 & $\mathrm{mg} / \mathrm{L}$ & $C_{\mathrm{P} 2(\mathrm{Cl})}=\left(J_{\mathrm{B}} A_{\mathrm{ROmem}}\right) / Q_{\mathrm{P} 2}$ & \\
\hline & & & $J_{\mathrm{Cl}}=\frac{B_{\mathrm{Cl}}}{1+\left(B_{\mathrm{Cl}} / J_{\mathrm{w}}\right)} C_{\mathrm{P} 1(\mathrm{Cl})}$ & {$[33]$} \\
\hline Permeate sodium adsorption ratio, SAR & 0.04 & & $S A R=\frac{\left[\mathrm{Na}^{+}\right]\left(\frac{\mathrm{meq}}{\mathrm{L}}\right)}{\mathrm{F}}$ & {$[17]$} \\
\hline \multirow[t]{3}{*}{ Required forward osmosis membrane area, $A_{\mathrm{FOmem}}$} & 571,000 & $\mathrm{~m}^{2}$ & $A_{\mathrm{FOmem}}=\left(Y_{\mathrm{FO}} Q_{\mathrm{F}}\right) / J_{\mathrm{w}}$ & \\
\hline & & & $J_{\mathrm{w}}=A\left\{\frac{\pi_{\mathrm{D}} \exp \left(-J_{w} S / D\right)-\pi_{\mathrm{F}} \exp \left(J_{w} / k\right)}{1+\left(B / J_{w}\right)\left[\exp \left(J_{w} / k\right)-\exp \left(-J_{w} S / D\right)\right]}\right\}$ & {$[31]$} \\
\hline & & & $\pi_{\mathrm{D}}=\left(\pi_{\mathrm{D}}-\pi_{\mathrm{P} 1}\right) /\left(\ln \left(\pi_{\mathrm{D}}\right)-\ln \left(\pi_{\mathrm{P} 1}\right)\right)$ & {$[36]$} \\
\hline \multirow[t]{2}{*}{ Required reverse osmosis membrane area, $A_{\text {ROmem }}$} & 84,000 & $\mathrm{~m}^{2}$ & $A_{\mathrm{ROmem}}=Q_{\mathrm{P} 2} / J_{\mathrm{w}}$ & \\
\hline & & & $J_{\mathrm{W}}=A\left(\Delta P_{\mathrm{RO}}-\pi_{\mathrm{D}}\right)$ & {$[36]$} \\
\hline Total integrated system membrane area, $A_{\text {TOTmem }}$ & 656,000 & $\mathrm{~m}^{2}$ & $A_{\text {TOTmem }}=A_{\text {FOmem }}+A_{\text {ROmem }}$ & \\
\hline \multirow[t]{2}{*}{ Specific energy consumption of reverse osmosis process, $S E C_{\mathrm{RO}}$} & 1.65 & $\mathrm{kWh} / \mathrm{m}^{3}$ & $S E C_{\mathrm{RO}}=W_{\mathrm{Pump}} / Q_{\mathrm{P} 2}$ & {$[36]$} \\
\hline & & & $W_{\text {Pump }}=\left[\left(\Delta P_{\mathrm{RO}}\left(Q_{\mathrm{P} 1}-\left(\eta_{\mathrm{PX}} Q_{\mathrm{D}}\right)\right)\right] / \eta_{\mathrm{Pump}}\right.$ & \\
\hline
\end{tabular}

Modeling results show that the integrated forward and reverse osmosis desalination process using second generation forward osmosis membranes can achieve rejections of $95.0 \%$ for boron and $99.9 \%$ for total dissolved solids when operating at $25 \%$ overall system water recovery (Table 2 ). The boron rejection rate depends on system recovery and varies between 80 and $99 \%$, while the total dissolved solids rejection is always greater than $99 \%$. Permeate boron and chloride concentrations for the modeled process are well below the limits required for agricultural irrigation, indicating the prospective application of this integrated seawater desalination process for producing agricultural irrigation water.

Bench-scale testing has not yet been performed to demonstrate the efficacy of boron and chloride removal to low levels suitable for agricultural irrigation using an integrated forward osmosis and reverse osmosis desalination process. However, published research indicates that it is a practicable desalination process, and modeling of an integrated system using second- generation thin-film composite forward osmosis membranes demonstrates that stringent boron and chloride limits for agriculture can be achieved with the integrated process.

\section{Integrated forward osmosis and reverse osmosis can potentially reduce the energy of desalination}

An integrated forward osmosis and reverse osmosis desalination process producing water for agricultural use can save energy compared to the conventional two-pass SWRO process illustrated in Fig. 1 because it achieves pretreatment for the reverse osmosis process and post-treatment for boron and chloride removal in a combined process. In the integrated system, the forward osmosis membranes replace conventional pretreatment by coagulation and granular media filtration or micro- or ultrafiltration, and second-stage reverse osmosis post-treatment is eliminated. 
We modeled the energy consumption of the integrated forward and reverse osmosis desalination process and compared the results to those from modeling we performed for a two-pass SWRO process operating under the same conditions. The integrated forward and reverse osmosis process has lower specific energy consumption $\left(\mathrm{kWh} / \mathrm{m}^{3}\right.$ of produced water) than the two-pass reverse osmosis process at all system recoveries. Fig. 3 and Table 3 compare the modeling results for specific energy consumption and required membrane area of the integrated forward and reverse osmosis process to a two-pass SWRO process. The modeling conditions and equations used for the integrated forward and reverse osmosis process are presented in Tables 1 and 2, respectively. Modeling of the two-pass SWRO process was based on a previous study [36], with recycling of second pass concentrate to the seawater feed and a fixed recovery of $95 \%$ for the second reverse osmosis pass. The pretreatment energy was taken to be $0.15 \mathrm{kWh} / \mathrm{m}^{3}$ of feed water.

Currently, there are no full-scale forward osmosis installations in operation, and therefore, the actual energy requirement of full-scale forward osmosis is unavailable for direct comparison to current SWRO pretreatment energy requirements. However, because the forward osmosis component of the integrated forward and reverse osmosis system consists of a draw solution pumped at low pressure, the required operating energy for forward osmosis can be estimated as equivalent to the pumping energy required in a micro- or

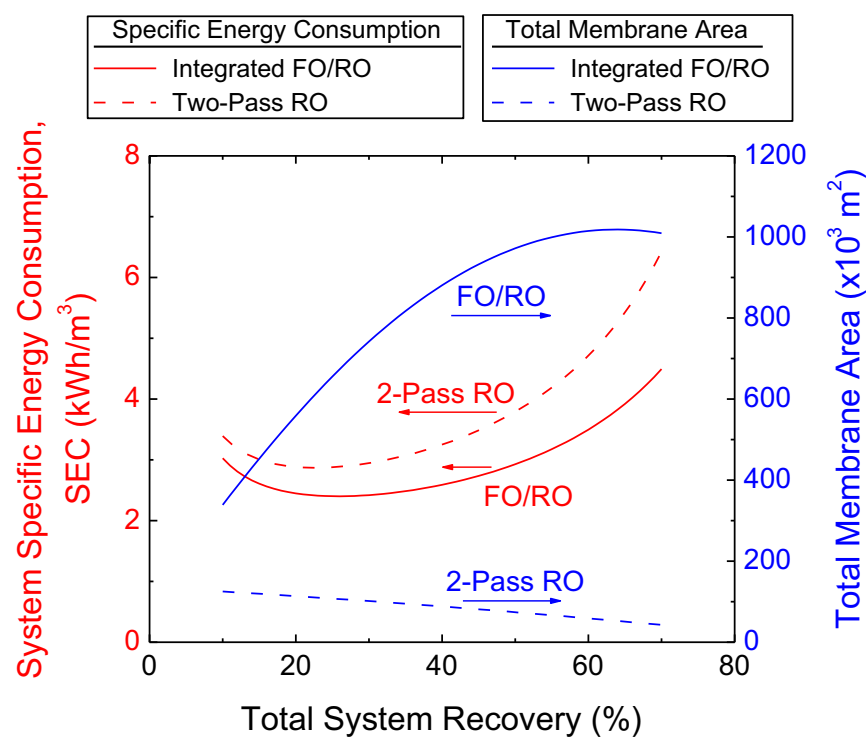

Fig. 3. Modeling results for specific energy consumption (SEC) and total membrane area of an integrated forward and reverse osmosis seawater desalination process compared to a two-pass reverse osmosis process.

Table 3

Modeling results for specific energy consumption (SEC) and total membrane area of an integrated forward and reverse osmosis seawater desalination process compared to a two-pass reverse osmosis process.

\begin{tabular}{|c|c|c|c|c|}
\hline \multirow{2}{*}{$\begin{array}{l}\text { Total } \\
\text { system } \\
\text { recovery }\end{array}$} & \multicolumn{2}{|c|}{ Integrated $\mathrm{FO} / \mathrm{RO}$ process } & \multicolumn{2}{|c|}{ Two-pass RO process } \\
\hline & $\begin{array}{l}S E C\left(\mathrm{kWh} / \mathrm{m}^{3}\right. \\
\text { produced } \\
\text { water })\end{array}$ & $\begin{array}{l}\text { Total } \\
\text { membrane } \\
\text { area }\left(\mathrm{m}^{2}\right)\end{array}$ & $\begin{array}{l}S E C\left(\mathrm{kWh} / \mathrm{m}^{3}\right. \\
\text { produced } \\
\text { water })\end{array}$ & $\begin{array}{l}\text { Total } \\
\text { membrane } \\
\text { area }\left(\mathrm{m}^{2}\right)\end{array}$ \\
\hline $10 \%$ & 3.03 & 339,000 & 3.39 & 125,000 \\
\hline $25 \%$ & 2.40 & 656,000 & 2.88 & 108,000 \\
\hline $50 \%$ & 2.93 & 972,000 & 3.79 & 74,000 \\
\hline $70 \%$ & 4.49 & $1,009,000$ & 6.43 & 43,000 \\
\hline
\end{tabular}

ultrafiltration system [37]. For modeling purposes, the forward osmosis system energy requirement was assumed to be equivalent to the micro- or ultrafiltration pretreatment energy requirement for two-pass SWRO.

Modeling results indicate that the specific energy consumption for both the integrated forward and reverse osmosis process and the two-pass reverse osmosis process is at a minimum for a system water recovery of approximately 25\%. The increasing osmotic pressure of the flowstream treated by the reverse osmosis system (diluted draw solution for the integrated process and pretreated seawater for the two-pass SWRO process) drives the increasing energy consumption at higher system recovery. Below approximately 25\% recovery, the energy requirement of draw solution pumping (for the integrated forward and reverse osmosis process) and energy of feed water pretreatment (for the two-pass SWRO process) for the large seawater feed flowrates result in an overall increase in specific energy consumption. In addition, a tradeoff exists between reduced specific energy consumption and an increase in required membrane area. The savings in energy and energy costs for the integrated process must be considered in the context of increased required membrane area and its associated capital costs.

Boron is not completely rejected by the forward osmosis membrane in the integrated forward and reverse osmosis desalination process, even assuming second-generation forward osmosis membrane characteristics. If not removed, boron from the seawater feed would accumulate in the closed draw solution loop of the integrated process and drive boron flux across the reverse osmosis membrane into the product water. We used the integrated forward and reverse osmosis process model to determine the proportion of the draw solution flowrate that must be bled from the process at steady state operation to maintain the target boron concentration in the product water. For target boron concentrations ranging from $0.3-1.0 \mathrm{mg} / \mathrm{L}$, the corresponding ratios of bleed flowrate to the draw solution flowrate range from $23 \%-5 \%$, with lower bleed ratios required for higher allowable boron concentrations in the product water.

The bleed stream from the draw solution of the integrated process could be treated by ion exchange to selectively remove accumulated boron before returning the treated bleed stream back to the draw solution. Adding draw solute to the bleed stream after it is treated to remove boron but before it is returned to the draw solution is also a potential mechanism to replenish draw solute that is lost through reverse salt flux across the forward osmosis membrane into the seawater feed and flux across the reverse osmosis membrane into the product water.

\section{Other benefits realized from integrating forward osmosis and reverse osmosis}

In addition to energy savings, an integrated forward osmosis and reverse osmosis desalination process to produce water for agricultural irrigation has several potential benefits when compared to conventional SWRO. The key benefits include (i) chemical storage and feed systems may be reduced for capital and operations and maintenance cost savings, (ii) water quality is improved for increased consumer confidence and reduced process piping costs, and (iii) the overall sustainability of the desalination process is improved.

The pretreatment function of the forward osmosis unit in the integrated forward and reverse osmosis process can achieve capital and operations and maintenance cost savings by eliminating some pretreatment chemical storage and feed facilities that would be required for a conventional granular media filtration pretreatment system or micro- or ultrafiltration pretreatment. 
Reductions in the size of other chemical systems are anticipated due to the expected reduction in reverse osmosis membrane cleaning frequency and intensity following pretreatment by forward osmosis. Specifically, the improved rejection of dissolved organic matter by forward osmosis pretreatment compared to current conventional and membrane pretreatment systems will reduce fouling of the reverse osmosis membranes and associated cleaning requirements.

The extent of permeate stabilization and remineralization by post-treatment chemical addition may also be reduced. Currently, the most commonly used post-treatment system in seawater desalination plants worldwide is the addition of carbon dioxide $\left(\mathrm{CO}_{2}\right)$ followed by lime $\left(\mathrm{Ca}(\mathrm{OH})_{2}\right)$. Carbon dioxide adds carbonate alkalinity for buffering capacity, and lowers the $\mathrm{pH}$ to facilitate the subsequent lime addition process. Lime enriches the water with total hardness and alkalinity, which help minimize corrosion [38].

For both a conventional SWRO desalination process and the integrated forward osmosis and reverse osmosis process, some amount of solute will pass through the reverse osmosis membrane into the permeate. For the integrated process, the high draw solution concentration will result in draw solute flux through the reverse osmosis membrane into the permeate that will be much higher than the corresponding solute flux from firstpass reverse osmosis permeate into the second-pass reverse osmosis permeate in a two-pass reverse osmosis process. However, the flux of draw solute into the permeate in the integrated process can be beneficial if a draw solute is selected that would achieve some of the goals of permeate stabilization and remineralization. Magnesium sulfate $\left(\mathrm{MgSO}_{4}\right)$ is a good candidate as a draw solution because it has the characteristics that minimize its reverse flux through the forward osmosis membrane. In addition, the $\mathrm{MgSO}_{4}$ that passes through the reverse osmosis membrane into the permeate would serve to add desirable hardness to the finished water. Magnesium sulfate flux through the reverse osmosis membrane into the permeate is a function of system water recovery, with decreasing $\mathrm{MgSO}_{4}$ flux with increasing recovery. The modeling results for the integrated forward and reverse osmosis desalination process indicate that draw solute flux would contribute approximately $370 \mathrm{mg} / \mathrm{L} \mathrm{of} \mathrm{MgSO}_{4}$ to the finished water at a system recovery of $25 \%$. This permeate magnesium concentration results in a very low SAR that is desirable for irrigation purposes (Table 2).

The improved water quality from the forward osmosis pretreatment in the integrated forward and reverse osmosis desalination process has benefits in addition to reduced fouling of the reverse osmosis membranes. The double membrane barrier to potential contaminants can improve consumer confidence in the finished water quality. Another potential benefit is capital cost savings for process piping. Downstream of the forward osmosis unit, the $\mathrm{MgSO}_{4}$ draw solution is less corrosive than the comparable pretreated seawater in a conventional SWRO facility. In conventional SWRO plants, the high level of chlorides in seawater (approximately $19,000 \mathrm{mg} / \mathrm{L}$ ) requires the use of super duplex stainless steel alloys for process piping to resist corrosion. These alloys are several times more expensive than standard austenitic stainless steels such as Type 316 .

The improved sustainability of the integrated forward and reverse osmosis desalination process is another benefit beyond energy savings. The integrated process is a more sustainable practice than conventional SWRO because fewer chemicals and reduced volumes of chemicals are used during treatment, in addition to its reduced energy consumption. More sustainable water treatment is inherently beneficial, and the improved sustainability of the integrated forward and reverse osmosis process can also increase acceptance of the process and help lower barriers to its implementation.

\section{Concluding remarks}

Desalinating seawater for agricultural irrigation using a novel integrated forward osmosis and reverse osmosis process has the potential to achieve stringent product water quality requirements while consuming less energy than a conventional SWRO facility. Irrigated agriculture will continue to drive global water demands, and an integrated forward and reverse osmosis desalination process has the potential to increase the available water supply for agriculture in a way that is more sustainable than the current SWRO process.

In the integrated desalination process, the forward osmosis unit functions as a pretreatment step for the subsequent reverse osmosis unit. Although research has demonstrated that the forward osmosis process has a much lower organic fouling propensity than reverse osmosis, a better understanding of forward osmosis biofouling and scaling behavior can further improve the performance of the integrated desalination process. The development of fouling resistant forward osmosis membranes and improved design of forward osmosis membrane modules are important areas of continued research to control and mitigate fouling in the forward osmosis process.

The development and commercialization of second-generation forward osmosis membranes with improved boron and salt rejection will also be an important contribution to the advancement of the integrated forward and reverse osmosis desalination concept. Managing the tradeoff between specific energy consumption and membrane area requirements at low system recoveries and quantifying the potential cost savings of the integrated forward and reverse osmosis process is an area of future study. Optimizing draw solution bleed and treatment for boron removal is a challenge for implementing the integrated forward and reverse osmosis process.

The potential benefits of the integrated forward and reverse osmosis desalination process extend beyond energy and cost savings. By using fewer treatment chemicals and prolonging the life of treatment equipment, the integrated forward and reverse osmosis desalination process improves the sustainability of a process that will be an increasingly important contributor to solving global water supply challenges.

\section{Nomenclature}

A membrane water permeability coefficient

$A_{\text {FOmem }}$ required forward osmosis membrane area

$A_{\text {ROmem }}$ required reverse osmosis membrane area

$A_{\text {TOTmem }}$ total integrated system membrane area

$B_{\mathrm{B}} \quad$ membrane permeability coefficient for boron

$B_{\mathrm{Cl}} \quad$ membrane permeability coefficient for chloride

$B_{\left(\mathrm{MgSO}_{4}\right)}$ membrane permeability coefficient for $\mathrm{MgSO}_{4}$ draw solute

$C_{\mathrm{D}\left(\mathrm{MgSO}_{4}\right)}$ draw solution $\mathrm{MgSO}_{4}$ concentration

$C_{\mathrm{F}(\mathrm{B})}$ seawater feed boron concentration

$C_{\mathrm{F}(\mathrm{Cl})} \quad$ seawater feed chloride concentration

$C_{\mathrm{F}\left(\mathrm{MgSO}_{4}\right)}$ seawater feed concentration of $\mathrm{MgSO}_{4}$ draw solute

$C_{\mathrm{F}(\mathrm{TDS})}$ seawater feed total dissolved solids concentration

$C_{\mathrm{P} 1(\mathrm{~B})}$ forward osmosis process permeate boron concentration

$C_{\mathrm{P} 1(\mathrm{Cl})}$ forward osmosis process permeate chloride concentration

$C_{\mathrm{P} 2(\mathrm{~B})}$ reverse osmosis process permeate boron concentration

$C_{\mathrm{P} 2(\mathrm{Cl})}$ reverse osmosis process permeate chloride concentration

$D_{\left(\mathrm{MgSO}_{4}\right)}$ bulk diffusion coefficient of $\mathrm{MgSO}_{4}$ draw solute in water

$\Delta P_{\mathrm{RO}} \quad$ reverse osmosis process operating pressure multiplier

$\eta_{\text {Pump }}$ reverse osmosis process high pressure pump efficiency

$\eta_{\mathrm{PX}} \quad$ pressure exchanger efficiency

$J_{\mathrm{B}} \quad$ boron flux

$J_{\mathrm{Cl}} \quad$ chloride flux

Jw water flux 
$k \quad$ mass transfer coefficient of feed solutes

$n$ number of dissolved species created by draw solute

$\pi_{\mathrm{C}} \quad$ forward osmosis process concentrate osmotic pressure

$\pi_{\mathrm{D}} \quad$ draw solution osmotic pressure

$\pi_{\mathrm{F}} \quad$ seawater feed osmotic pressure

$\pi_{\mathrm{P} 1} \quad$ forward osmosis process permeate osmotic pressure

$Q_{D} \quad$ draw solution flow rate multiplier

$Q_{\mathrm{F}} \quad$ seawater feed flow rate

$Q_{\mathrm{P} 1} \quad$ forward osmosis process permeate flow rate

$Q_{\mathrm{P} 2} \quad$ reverse osmosis process permeate flow rate

$R_{\mathrm{B}} \quad$ boron rejection

$R_{\mathrm{Cl}} \quad$ chloride rejection

$R_{\mathrm{FO}(\mathrm{B})} \quad$ forward osmosis process boron rejection

$R_{\mathrm{FO}(\mathrm{Cl})}$ forward osmosis process chloride rejection

$R_{\mathrm{g}} \quad$ ideal gas constant

$R_{\mathrm{RO}(\mathrm{B})} \quad$ reverse osmosis process boron rejection

$R_{\mathrm{RO}(\mathrm{Cl})}$ reverse osmosis process chloride rejection

$R_{\mathrm{T}(\mathrm{B})} \quad$ total integrated system boron rejection

$R_{\mathrm{T}(\mathrm{Cl})} \quad$ total integrated system chloride rejection

$S$ membrane structural parameter

SAR Sodium adsorption ratio

$S E C_{R O} \quad$ specific energy consumption of reverse osmosis process

$T$ absolute temperature

$W_{\text {Pump }} \quad$ work of high pressure reverse osmosis process pump

$Y_{\mathrm{FO}} \quad$ forward osmosis process recovery

$Y_{\mathrm{T}} \quad$ total integrated system recovery

\section{Acknowledgment}

Ngai Yin Yip was supported by the Graduate Fellowship Program of the Environment and Water Industrial Development Council of Singapore. Professor Menachem Elimelech acknowledges the support of the World Class University (WCU) Program (Case III) through the National Research Foundation of Korea and the Ministry of Education, Science and Technology (R33-10046).

\section{References}

[1] UNESCO, The 3rd United Nations World Water Development Report: Water in a Changing World, United Nations Educational, Scientific, and Cultural Organization, 2009.

[2] C.J. Vörösmarty, P. Green, J. Salisbury, R.B. Lammers, Global water resources: vulnerability from climate change and population growth, Science 289 (2000) 284-288.

[3] C.J. Vörösmarty, C. Leveque, C. Revenga, Fresh Water, in: R. Hassan, R. Scholes, N. Ash (Eds.), Ecosystems and Human Well-Being: Current State and Trends, Island Press, Washington, DC, 2005, pp. 165-207.

[4] J.A. Foley, N. Ramankutty, K.A. Brauman, E.S. Cassidy, J.S. Gerber, M. Johnston, N.D. Mueller, C. O'Connell, D.K. Ray, P.C. West, C. Balzer, E.M. Bennett, S.R. Carpenter, J. Hill, C. Monfreda, S. Polasky, J. Rockstrom, J. Sheehan, S. Siebert, D. Tilman, D.P.M. Zaks, Solutions for a cultivated planet, Nature 478 (2011) 337-342.

[5] UNDP, Beyond Scarcity: Power, Poverty, and the Global Water Crisis, Human Development Report, United Nations Development Programme, New York, 2006, p. 440.

[6] M.A. Shannon, P.W. Bohn, M. Elimelech, J.G. Georgiadis, B.J. Marinas, A.M. Mayes, Science and technology for water purification in the coming decades, Nature 452 (2008) 301-310.

[7] G.W. Miller, Integrated concepts in water reuse: managing global water needs, Desalination 187 (2006) 65-75.

[8] M. Elimelech, W.A. Phillip, The future of seawater desalination: energy, technology, and the environment, Science 333 (2011) 712-717.

[9] L.F. Greenlee, D.F. Lawler, B.D. Freeman, B. Marrot, P. Moulin, Reverse osmosis desalination: water sources, technology, and today's challenges, Water Res. 43 (2009) 2317-2348.

[10] Committee on Advancing Desalination Technology of the National Research Council (U.S.), Desalination: A National Perspective, National Academies Press, Washington, DC, 2008.
[11] R. Semiat, Energy issues in desalination processes, Environ. Sci. Technol. 42 (2008) 8193-8201.

[12] L.A. Hoover, W.A. Phillip, A. Tiraferri, N.Y. Yip, M. Elimelech, Forward with osmosis: emerging applications for greater sustainability, Environ. Sci. Technol. (2011).

[13] M. Wilf, The Guidebook to Membrane Desalination Technology, 2007.

[14] C. Fritzmann, J. Löwenberg, T. Wintgens, T. Melin, State-of-the-art of reverse osmosis desalination, Desalination 216 (2007) 1-76.

[15] Desalination Committee, Seawater Desalination Power Consumption, White Paper, WateReuse Association, Alexandria, VA, 2011, p. 16.

[16] World Health Organization, Guidelines for Drinking-Water Quality, Geneva, Switzerland, 2011.

[17] R.S. Ayers, D.W. Westcot, Water quality for agriculture, third ed., Food and Agriculture Organization of the United Nations, Rome, Italy, 1985.

[18] A. Tal, Seeking sustainability: Israel's evolving water management strategy, Science 313 (2006) 1081-1084.

[19] J.M. Beltrán, S. Koo-Oshima, Water desalination for agricultural applications, in: Food and Agriculture Organization of the Nations (Ed.), Proceedings of the FAO Expert Consultation on Water Desalination for Agricultural Applications, FAO, Rome Italy, 2006.

[20] P. Glueckstern, M. Priel, Optimization of boron removal in old and new SWRO systems, Desalination 156 (2003) 219-228.

[21] A. Sagiv, R. Semiat, Analysis of parameters affecting boron permeation through reverse osmosis membranes, J. Membr. Sci. 243 (2004) 79-87.

[22] G.M. Geise, H.B. Park, A.C. Sagle, B.D. Freeman, J.E. McGrath, Water permeability and water/salt selectivity tradeoff in polymers for desalination, J. Membr. Sci. 369 (2011) 130-138.

[23] T.Y. Cath, A.E. Childress, M. Elimelech, Forward osmosis: principles, applications, and recent developments, J. Membr. Sci. 281 (2006) 70-87.

[24] A. Achilli, T.Y. Cath, A.E. Childress, Selection of inorganic-based draw solutions for forward osmosis applications, J. Membr. Sci. 364 (2010) 233-241.

[25] B. Mi, M. Elimelech, Organic fouling of forward osmosis membranes: fouling reversibility and cleaning without chemical reagents, J. Membr. Sci. 348 (2010) 337-345.

[26] O.A. Bamaga, A. Yokochi, B. Zabara, A.S. Babaqi, Hybrid FO/RO desalination system: preliminary assessment of osmotic energy recovery and designs of new FO membrane module configurations, Desalination 268 (2011) 163-169.

[27] O.A. Bamaga, A. Yokochi, E.G. Beaudry, Application of forward osmosis in pretreatment of seawater for small reverse osmosis desalination units, Desalination Water Treat. 5 (2009) 183-191.

[28] S. Zhao, L. Zou, D. Mulcahy, Brackish water desalination by a hybrid forward osmosis-nanofiltration system using divalent draw solute, Desalination 284 (2012) 175-181.

[29] C.H. Tan, H.Y. Ng, A novel hybrid forward osmosis-nanofiltration (FO-NF) process for seawater desalination: draw solution selection and system configuration, Desalination Water Treat. 13 (2010) 356-361.

[30] T.Y. Cath, N.T. Hancock, C.D. Lundin, C. Hoppe-Jones, J.E. Drewes, A multibarrier osmotic dilution process for simultaneous desalination and purification of impaired water, J. Membr. Sci. 362 (2010) 417-426.

[31] W.A. Phillip, J.S. Yong, M. Elimelech, Reverse draw solute permeation in forward osmosis: modeling and experiments, Environ. Sci. Technol. 44 (2010) 5170-5176.

[32] N.T. Hancock, T.Y. Cath, Solute coupled diffusion in osmotically driven membrane processes, Environ. Sci. Technol. 43 (2009) 6769-6775

[33] X. Jin, C.Y. Tang, Y. Gu, Q. She, S. Qi, Boric acid permeation in forward osmosis membrane processes: modeling, experiments, and implications, Environ. Sci. Technol. 45 (2011) 2323-2330.

[34] A. Tiraferri, N.Y. Yip, W.A. Phillip, J.D. Schiffman, M. Elimelech, Relating performance of thin-film composite forward osmosis membranes to support layer formation and structure, J. Membr. Sci. 367 (2011) 340-352.

[35] R. Wang, L. Shi, C.Y. Tang, S. Chou, C. Qiu, A.G. Fane, Characterization of novel forward osmosis hollow fiber membranes, J. Membr. Sci. 355 (2010) $158-167$.

[36] A. Zhu, P.D. Christofides, Y. Cohen, Minimization of energy consumption for a two-pass membrane desalination: effect of energy recovery, membrane rejection and retentate recycling, J. Membr. Sci. 339 (2009) 126-137.

[37] R.L. McGinnis, M. Elimelech, Global challenges in energy and water supply: the promise of engineered osmosis, Environ. Sci. Technol. 42 (2008) 8625-8629.

[38] L. Birnhack, N. Voutchkov, O. Lahav, Fundamental chemistry and engineering aspects of post-treatment processes for desalinated water-a review, Desalination 273 (2011) 6-22.

[39] N.Y. Yip, M. Elimelech, Performance limiting effects in power generation from salinity gradients by pressure retarded osmosis, Environ. Sci. Technol. 45 (2011) 10273-10282.

[40] N.Y. Yip, A. Tiraferri, W.A. Phillip, J.D. Schiffman, L.A. Hoover, Y.C. Kim, M. Elimelech, Thin-film composite pressure retarded osmosis membranes for sustainable power generation from salinity gradients, Environ. Sci. Technol. 45 (2011) 4360-4369.

[41] V.M.M. Lobo, Mutual diffusion coefficients in aqueous electrolyte solutions, Pure Appl. Chem. 65 (1993) 2613-2640.

[42] H. Hyung, J.-H. Kim, A mechanistic study on boron rejection by sea water reverse osmosis membranes, J. Membr. Sci. 286 (2006) 269-278. 